\title{
Efficacy of Topiramate in Children with Refractory Status Epilepticus
}

\author{
Mustafa Kahriman, Daniela Minecan, Ekrem Kutluay, Linda Selwa, and Ahmad Beydoun \\ Department of Neurology, University of Michigan Health System, Ann Arbor, Michigan, U.S.A.
}

\begin{abstract}
Summary: Purpose: Status epilepticus (SE) is a life-threatening medical condition associated with significant morbidity and mortality that requires urgent medical intervention. Although several agents are available to treat SE, they occasionally fail to abort seizure activity. Topiramate (TPM) was anecdotally reported to be effective in adult patients with refractory SE. In this study, we evaluated the efficacy of TPM administered to children with this condition.

Methods: We retrospectively reviewed the pediatric SE database at the University of Michigan Medical Center and identified three children with refractory SE who were treated with TPM. Those children failed to respond to treatment with benzodiazepines, phenytoin, phenobarbital, midazolam, or pento-
\end{abstract}

barbital. Additional treatment with TPM was administered by nasogastric tube. All patients were continuously monitored by 21-channel digital EEG machines, and the diagnosis of SE was made by a board-certified neurophysiologist.

Results: The ages of the three children were 4.5 months, 34 months, and 11 years. TPM was initiated at $2 \mathrm{mg} / \mathrm{kg} / \mathrm{day}$ in two children and at $3 \mathrm{mg} / \mathrm{kg} / \mathrm{day}$ in the third. The status was terminated in all three children within $24 \mathrm{~h}$ of maintenance therapy with TPM at 5-6 mg/kg/day.

Conclusions: These results support the potential efficacy of TPM for children with refractory SE. Larger prospective series are needed to confirm those results. Key Words: TopiramateSafety-Status epilepticus-Efficacy-Antiepileptic drugs.
Status epilepticus (SE) in childhood is a serious and potentially life-threatening medical condition that requires immediate medical intervention (1). It is estimated that $0.4-0.8 \%$ of children will experience an episode of convulsive SE before age 15 years (2). Various treatment protocols have been advocated to treat SE in children including benzodiazepines (BZDs), phenytoin (PHT)/fosphenytoin (FOS), barbiturates, paraldehyde, and general anesthesia (3). Although these agents are usually successful in terminating seizure activity, some seizures remain refractory and require additional intervention. Refractory SE has been defined as seizures lasting $>60$ min despite treatment with BZDs and an adequate intravenous loading dose of a standard anticonvulsant drug (AED) (4) or the persistence of seizure activity despite appropriate medical and AED therapy (5). Refractory SE in childhood was shown to be associated with a high morbidity and a mortality rate of $\leq 32 \%$ (6).

Topiramate (TPM) is a second-generation AED with multiple mechanisms of action including blockade of voltage-sensitive $\mathrm{Na}^{+}$and L-type $\mathrm{Ca}^{2+}$ channels, en-

\footnotetext{
Accepted June 25, 2003.

Address correspondence and reprint requests to Dr. A. Beydoun at University of Michigan Health System, 1500 E. Medical Center Drive, UH1B300/0036, Ann Arbor, MI 48109-0036, U.S.A. E-mail: beydoun@umich.edu
}

hancement of $\gamma$-aminobutyric acid (GABA) activity at $\mathrm{GABA}_{\mathrm{A}}$ receptors, inhibition of kainate-evoked currents, and inhibition of certain carbonic anhydrase isozymes (7). It was recently reported to be beneficial in the treatment of adults with refractory SE $(8,9)$. In this study, we evaluated our experience in using TPM in children with this condition.

\section{MATERIALS AND METHODS}

We retrospectively reviewed the pediatric SE database at the University of Michigan Medical Center. Over a 14-month period, we identified a total of three children who were treated with TPM for refractory SE. TPM tablets were crushed and administered by nasogastric tube. All patients were continuously monitored by 21-channel digital EEG machines (Nicolet BSMI 6000), and the diagnosis of SE was made by a board-certified neurophysiologist based on clinical and EEG findings.

\section{RESULTS}

\section{Case 1}

The patient was a 34-month-old boy with a history of severe static encephalopathy, schizencephaly, hydrocephalus requiring ventriculoperitoneal shunt, asthma, and recurrent aspiration pneumonias. The boy had a history of infrequent tonic and generalized tonic-clonic 
seizures that clustered at the time of his pulmonary infections and for which he was maintained on a regimen of carbamazepine (CBZ) and phenobarbital (PB). He was admitted with convulsive SE characterized by frequent generalized tonic-clonic seizures without recovering his baseline level of consciousness between seizures. Each seizure lasted from 11 to $40 \mathrm{~s}$, with seizure-free intervals lasting from $40 \mathrm{~s}$ up to $4 \mathrm{~min}$. Initial treatment consisted of lorazepam (LZP; total dose of $5 \mathrm{mg} ; 0.3 \mathrm{mg} / \mathrm{kg}$ ) and a loading dose of PHT $(20 \mathrm{mg} / \mathrm{kg})$ intravenously. Although the seizure activity appeared to be controlled, the EEG was diagnostic of electrographic SE of right frontal origin characterized by continuous spike-and-wave activity with a maximal field at the Fp2 and F4 electrode sites. Consequently, treatment with pentobarbital (PTB) was initiated, and the dose was titrated until a burst-suppression EEG pattern was achieved. Multiple attempts to taper him off PTB were unsuccessful despite the addition of intravenous valproate (VPA). The patient was switched to midazolam (MDL)-induced coma with recurrence of electrographic SE at every attempt to taper. The patient remained in drug-induced coma, with the EEG revealing a burstsuppression pattern. Additional treatment with TPM was commenced via nasogastric tube on day 13 after admission, at a dose of $1 \mathrm{mg} / \mathrm{kg}$ b.i.d. (17 $\mathrm{mg}$ b.i.d.) and was titrated to $6 \mathrm{mg} / \mathrm{kg} / \mathrm{day}(50 \mathrm{mg}$ b.i.d.) within $72 \mathrm{~h}$. The SE was aborted on the day TPM was administered at 6 $\mathrm{mg} / \mathrm{kg} /$ day (Fig. 1). The patient died $\sim 7$ months after his discharge from the hospital. The cause of death was at- tributed to sepsis and respiratory arrest as complications from Pseudomonas pneumonia. During those 7 months, he was evaluated several times in the outpatient pediatric clinics and remained seizure free while maintained on TPM monotherapy at a dose of $100 \mathrm{mg} /$ day.

\section{Case 2}

In an 11-year-old girl with a history of aplastic anemia and aspergillosis, and no prior history of epilepsy, thrombocytopenia, massive pulmonary hemorrhage, respiratory distress, and cardiopulmonary arrest developed, requiring intubation and resuscitation by emergency medical services. Twenty-four hours later, although still intubated, the girl was awake and was following simple commands. Because of intermittent twitching of the left hand, she was administered a loading dose of $650 \mathrm{mg}$ of PHT $(15.5 \mathrm{mg} / \mathrm{kg})$ and received $2-4 \mathrm{mg} \mathrm{LZP}$ as needed. EEG revealed generalized background slowing and intermittent bitemporal independent slowing. A day later, she was found to be unresponsive. A repeated EEG was diagnostic for nonconvulsive SE, with numerous electrographic seizures originating independently from the left temporal, left frontocentral, and right occipital regions. The seizures lasted between 20 and 180 s and recurred every 2 to $10 \mathrm{~min}$. Although most of the seizures were subclinical, some were accompanied by chewing movements and lip smacking. The interictal EEG revealed diffuse polymorphic deltatheta slowing, as well as intermittent left frontal (maximum at the Fp1 and F3 electrode sites) and occasional

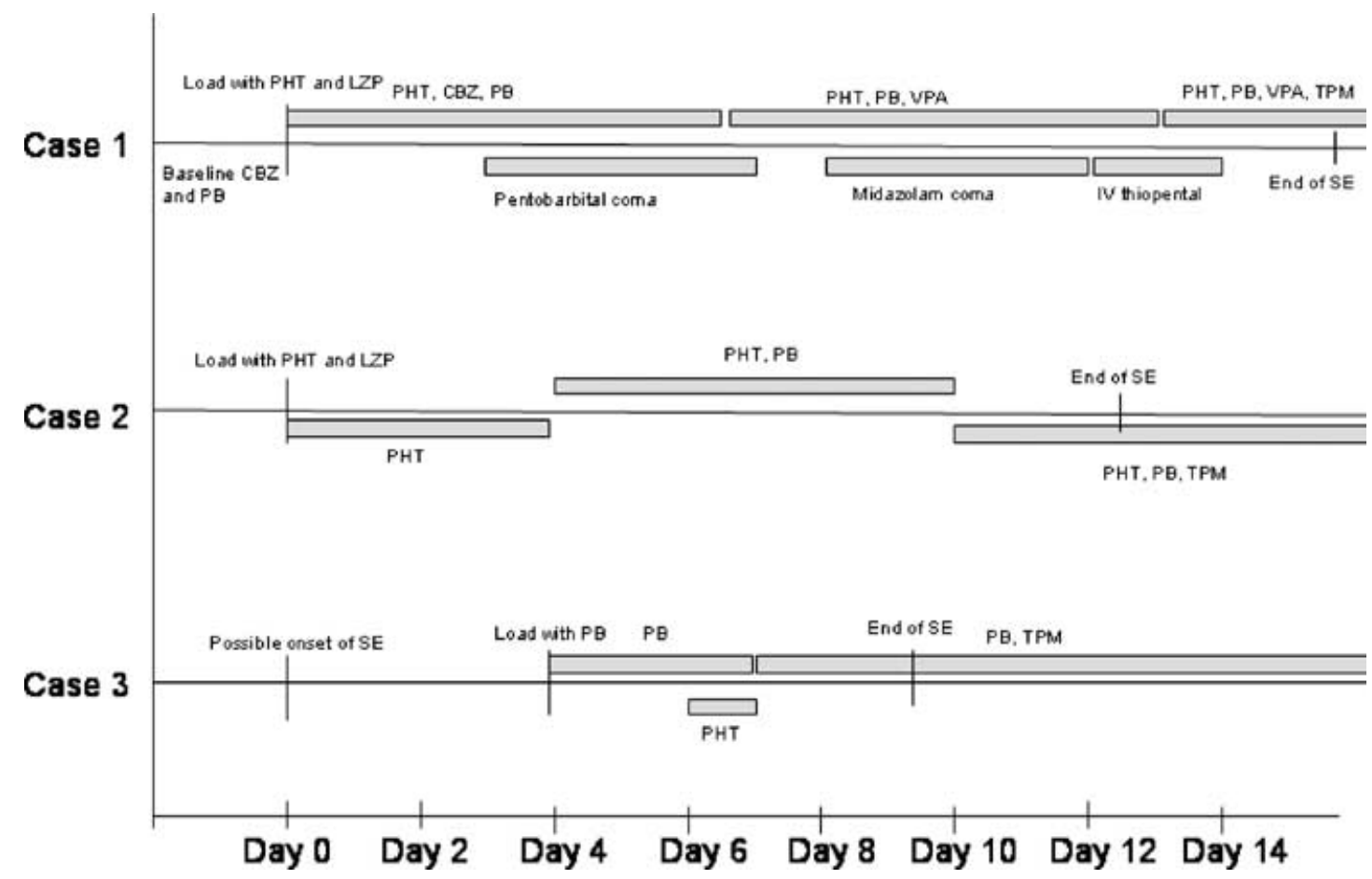

FIG. 1. Anticonvulsant treatment and course of the SE in three cases. CBZ, carbamazepine; LZP, lorazepam; PB, phenobarbital; PHT, phenytoin; TPM, topiramate (Topamax); VPA, sodium valproate; SE, status epilepticus. 
right frontotemporal spikes (maximum at the F8 electrode site). The patient failed to respond to a loading dose and maintenance therapy with $\mathrm{PB}$, and the SE, both clinical and electrographic, persisted despite a free PHT level of $3.3 \mu \mathrm{g} / \mathrm{ml}$ and a PB level of $119 \mu \mathrm{g} / \mathrm{ml}$. The patient continued to have multiple electrographic seizures without recovery of baseline mental status between the seizures. Treatment with TPM, $1 \mathrm{mg} / \mathrm{kg}$ b.i.d. (42 mg b.i.d. through the nasogastric tube) was initiated 10 days after the onset of the SE and titrated to $200 \mathrm{mg} /$ day $(5 \mathrm{mg} / \mathrm{kg} /$ day) over 3 days. Within $24 \mathrm{~h}$ of TPM treatment at $5 \mathrm{mg} / \mathrm{kg} /$ day, the SE was aborted both clinically and electrographically, and the patient was extubated (Fig. 1). The patient died 4 months after her discharge from the hospital. The cause of death was an intracerebral hemorrhage, a likely complication of her aplastic anemia. During those 4 months, she remained seizure free with TPM monotherapy at a daily dose of $200 \mathrm{mg} /$ day.

\section{Case 3}

A four-and-half-month-old baby boy born at 27 weeks' gestational age was hospitalized after an episode of prolonged apnea. He was found to have oxygen desaturations down to $60 \%$. Brain magnetic resonance imaging (MRI) showed a lesion in the left temporal lobe. An EEG was diagnostic of nonconvulsive electrographic SE of left temporal origin. Treatment with PB (loading dose of $20 \mathrm{mg} / \mathrm{kg}$; maintenance dose of $5 \mathrm{mg} / \mathrm{kg}$ ) and PHT (loading dose of $20 \mathrm{mg} / \mathrm{kg}$; maintenance dose of $4.8 \mathrm{mg} / \mathrm{kg}$ ) was unsuccessful, and the patient remained in nonconvulsive electrographic SE. The boy appeared to be alert but was intermittently sleepy although easily arousable. Treatment with TPM was initiated at $3 \mathrm{mg} / \mathrm{kg} /$ day 7 days after the onset of SE, with the dose increased to $6 \mathrm{mg} / \mathrm{kg} /$ day $48 \mathrm{~h}$ later. The electrographic SE was terminated within $24 \mathrm{~h}$ of treatment with TPM at $6 \mathrm{mg} / \mathrm{kg} /$ day (Fig. 1). The patient remained seizure free with a combination of TPM, $4.8 \mathrm{mg} / \mathrm{kg} / \mathrm{day}$, and PB, $2 \mathrm{mg} / \mathrm{kg} / \mathrm{day}$. Because of an increase in the size of the lesion, the patient underwent resective surgery at age 11 months, and the pathology revealed a low-grade glioma. Since discharge from the hospital 12 months ago, the patient remains seizure free with a combination of PB, $16 \mathrm{mg} /$ day, and TPM, $50 \mathrm{mg} /$ day.

\section{DISCUSSION}

This is the first report to suggest that TPM is a useful option for the treatment of refractory SE in children. So far, no data permit the development of an evidence-based treatment algorithm for refractory SE in children (3). The approach has been based mostly on clinical experience and small published series. Although high-dose PTB is frequently administered for that condition, its use in children can be associated with morbidity and mortality, with the risk of complications being higher in neonates and young infants (10). Safer alternatives for the treatment of refractory SE in children are therefore needed.

Two recent reports, one consisting of a single case (8), and the other, of a series of six patients (9), showed that TPM can be an effective treatment for adults with refractory SE. In those reports, TPM was administered at daily doses ranging between 300 and 1,600 mg, and the SE was aborted from several hours up to 10 days after initiation of TPM therapy.

In addition, animal models have suggested that TPM administration can be associated with neuroprotective effects (11-13). In a kindling model of limbic SE in the rat, intraperitoneal administration of TPM at $40 \mathrm{mg} / \mathrm{kg}$ and $80 \mathrm{mg} / \mathrm{kg}$ led to significant reduction in the degree of hippocampal neuronal death (12). Similarly, when administered after recurrent seizures or SE, TPM demonstrated evidence of neuroprotection and improved cognitive function (13).

In our small series, TPM was efficacious in aborting SE in three children who were administered this drug. The small sample precludes us from making recommendations regarding starting dose, titration schedule, or target dose for TPM for the treatment of children with refractory SE. In two of our patients, TPM was initiated at $2 \mathrm{mg} / \mathrm{kg} /$ day and titrated to $\leq 5-6 \mathrm{mg} / \mathrm{kg} /$ day over a 3 -day period, and was started at $3 \mathrm{mg} / \mathrm{kg} /$ day in the third case and titrated to $6 \mathrm{mg} / \mathrm{kg} /$ day over a 48-h period. In all three cases, TPM therapy was not associated with short-term adverse events, and the SE was aborted within $24 \mathrm{~h}$ of maintenance therapy at $5-6 \mathrm{mg} / \mathrm{kg} /$ day. However, it is well established that treatment with TPM can lead to cognitive side effects, especially when the drug is quickly titrated or used at higher dosages. These adverse events are usually characterized by psychomotor slowing and a decline in attention and word-fluency measures $(14,15)$. The cognitive functions of our patients were not systematically evaluated. In the first case, there was no mention of cognitive dysfunction in the medical records, although it would have been difficult to evaluate because of the patient's profound mental retardation. The second child underwent neuropsychological and speech evaluations that revealed a working memory deficit and word-finding difficulties. Those cognitive dysfunctions were thought to be related either to TPM treatment or to the underlying static hypoxic encephalopathy. The third child was evaluated in the clinic on a number of occasions after his discharge from the hospital and did not experience cognitive dysfunction with TPM treatment. Because cognitive dysfunction can be associated with TPM treatment, cognitive measures should be regularly evaluated when patients are being treated with this drug.

Given the pharmacokinetic profile of TPM in infants and children, characterized by a higher mean plasma clearance compared with that in adolescents and adults, it is likely that a more aggressive starting dose and titration 
schedule would be well tolerated (16). Potential pharmacokinetic drug-drug interactions also could influence the target dose of TPM required for an effective response. In a double-blind, randomized clinical trial, adjunctive therapy with TPM at a median dose of $5.9 \mathrm{mg} / \mathrm{kg} /$ day was well tolerated and resulted in significant reduction of seizure frequency in children with seizures of partial onset (17). Higher daily maintenance doses of TPM administered during the open-label phase of this trial (range, $4-22 \mathrm{mg} / \mathrm{kg}$ ) (18) and to infants with infantile spasms ( $\leq 50 \mathrm{mg} / \mathrm{kg})(19)$ were reported to be safe and well tolerated.

In conclusion, although our results are encouraging, they can be considered only anecdotal evidence of efficacy of TPM for children with refractory SE. They should be confirmed by larger prospective clinical trials.

Acknowledgment: This study was presented during the scientific session at the Annual Meeting of the American Epilepsy Society, in Philadelphia, Pennsylvania, on December 4, 2001.

\section{REFERENCES}

1. Scott RC, Surtees RAH, Neville BGR. Status epilepticus: pathophysiology, epidemiology, and outcomes. Arch Dis Child 1998;79:73-7.

2. DeLorenzo RJ, Pellock JM, Towne AR, et al. Epidemiology of status epilepticus. J Clin Neurophysiol 1995;12:316-25.

3. Appleton R, Choonara I, Martland T, et al. The treatment of convulsive status epilepticus in children. Arch Dis Child 2000;83:415-9.

4. Mayer SA, Claasen J, Lokin J, et al. Refractory status epilepticus: frequency, risk factors, and impact on outcome. Arch Neurol 2002;59:205-10.
5. Shorvon S. Status epilepticus: its clinical features and treatment in children and adults. Cambridge: Cambridge University Press, 1994.

6. Sahin M, Menache CC, Holmes GL, et al. Outcome of severe refractory status epilepticus in children. Epilepsia 2001;42:1461-7.

7. Shank RP, Gardocki JF, Streeter AJ, et al. An overview of the preclinical aspects of topiramate: pharmacology, pharmacokinetics, and mechanism of action. Epilepsia 2000;41(suppl 1):S3-9.

8. Reuber M, Evans J, Bamford JM. Topiramate in drug-resistant complex partial status epilepticus [Letter]. Eur J Neurol 2002;9:111-2.

9. Towne AR, Garnett LK, Waterhause EJ, et al. The use of topiramate in refractory status epilepticus. Neurology 2003;60:332-4.

10. Kim SJ, Lee DY, Kim JS. Neurologic outcomes of pediatric epileptic patients with pentobarbital coma. Pediatr Neurol 2002;25:21720.

11. Yang Y, Shuaib A, Li Q, et al. Neuroprotection by delayed administration of topiramate in a rat model of middle cerebral artery embolization. Brain Res 1998;804:169-76.

12. Niebauer M, Gruenthal M. Topiramate reduces neuronal injury after experimental status epilepticus. Brain Res 1999;837:263-9.

13. Cha BH, Silveira DC, Liu X, et al. Effect of topiramate following recurrent and prolonged seizures during early development. Epilepsy Res 2002;51:217-32.

14. Martin R, Kuzniecky R, Ho S, et al. Cognitive side effects of topiramate, gabapentin, and lamotrigine in healthy young adults. Neurology 1999;52:321-7.

15. Tatum WO, French JA, Faught E, et al. Postmarketing experience with topiramate and cognition. Epilepsia 2001;42:1134-40.

16. Glauser TA, Miles MV, Tang P, et al. Topiramate pharmacokinetics in infants. Epilepsia 1999;40:788-91.

17. Elterman RD, Glauser TA, Wyllie E, et al. A double-blind, randomized trial of topiramate as adjunctive therapy for partial onset seizures in children. Neurology 1999;52:1338-44.

18. Ritter F, Glauser TA, Elterman RD, et al. Effectiveness, tolerability, and safety of topiramate in children with partial onset seizures. Epilepsia 2000;41(suppl 1):S82-5.

19. Glauser TA, Clark PO, McGee K. Long-term response to topiramate in patients with West syndrome. Epilepsia 2000;41(suppl 1): S91-4. 